
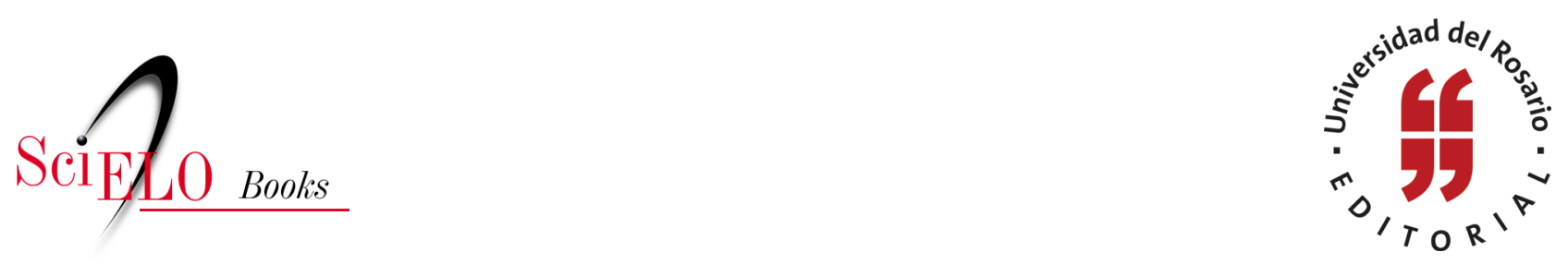

\title{
27. Una caricia que después no reclame amor
}

\author{
César Augusto Tapias Hernández
}

TAPIAS HERNÁNDEZ, C.A. Una caricia que después no reclame amor. In: Historias de familia:

Etnografía delirante sobre el amor, la violencia y las drogas [online]. Bogotá: Editorial Universidad del Rosario, 2014, pp. 119-122. Textos de ciencias humanas collection. ISBN: 978-958-738-543-4. https://doi.org/10.7476/9789587385434.0028.

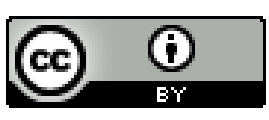

All the contents of this work, except where otherwise noted, is licensed under a Creative Commons Attribution 4.0 International license.

Todo o conteúdo deste trabalho, exceto quando houver ressalva, é publicado sob a licença Creative Commons Atribição 4.0.

Todo el contenido de esta obra, excepto donde se indique lo contrario, está bajo licencia de la licencia Creative Commons Reconocimento 4.0 . 


\title{
27. Una caricia que después no reclame amor
}

\author{
Siento que cada una de mis fibras de carne se enojan si no las \\ dejo hacer el amor con una bala. \\ Helí Ramírez, La ausencia del descanso
}

El tío Raúl es uno de los pelaos de la casa de mis abuelos. Él, Hétor y Ed, de pronto hasta Willi, aparecen así, como niños, en las historias de viejas anécdotas como la del matrimonio en secreto de Melia, como las aventuras de Osorio o de mi tío H. Donde los Tales, que son tantos, ha habido de todo, y estos que fueron primero los llorones también tienen sus historias. Raúl, por ejemplo, durante mucho tiempo terminó siendo el taxista de la familia, pues desvaraba a más de uno con carreras programadas por la misma familia, dizque para colaborarle al hombre: que recoja a las niñas de Ilsa, que lleve a Rigo a Niquía, que acompañe a César a grabar en el centro, etcétera, y es que resultaba hasta bacano tener transporte fijo, porque que fueran a recogerlo a uno donde uno estuviera no era cosa de todos los días... El "Mocho", como algunos le dicen al tío, dado que perdió uno de sus dedos de la mano derecha en una fábrica de embutidos, es hoy por hoy el jefe de personal del autoservicio los Tres Reyes, un minimercado que el primo Memo, un sobrino de mamita Gélica, tiene en el municipio de Apartadó.

Después de andar perdido un buen tiempo, Raúl reapareció en la casa de los abuelos, gordo, bien motilado y con la dentadura arreglada. Sus últimos tiempos fueron muy malos, según su propia evaluación. Dice que su familia nunca lo aceptó así: pobre y guerrero, como es él... Su esposa Patricia dizque anda en España camellando y de sus hijos, Santiago y Laura, poco o nada se sabe... Sin embargo, espera que los pelados se enteren de que él ha regresado por algunos días. Confía, pues, en que los chismosos del barrio les den aviso. 
Ahora, cuando su presencia goza de tener presencia, dice Raúl — muy defraudado, por cierto - , que los sueños son finalmente güevonadas, que uno lucha por ellos y a la final nada de nada... no quiere entonces el tío meterse con nadie y de las mujeres solo le interesa una caricia que después no reclame amor... Y se justifica mirando espejos cercanos, como el caso del primito que se ganó la vida y más de un canazo empapelando mulas... El primito ganó las lucas mandando gente pa' los nuevayores con merca, y una vez hasta él también se fue; pero la mujer no lo esperó cuando supo que lo agarraron: seis años y un día fue la condena; sin embargo, como el día podría ser un mes o un año más, la Jevita también voló a España para nunca volver... Hoy el primito, al menos, está con los hijos; al Raúl ni chance de eso le dieron. Según él, la familia de Patricia ha puesto a sus hijos en contra suya.

-A lo mejor me equivoco copiando las cosas de esta manera, pero nada me dice lo contrario.

En Apartadó se gana unos pesitos con los que vive bien, bebe y rumbea en el barrio Ortiz o en el Vélez que, según cuenta, son como la calle 70 en Medellín, calle para la fiesta con lugares como La Cuna del Son, si lo que quieres es oír salsa (esta no le puede faltar a un Tales), y muchos otros lugares donde no dejan de sonar vallenato ventiao.

- Allá todo es puro vallenato y pura AUC.

Dice Raúl que en ese pueblo ya lo conocen bien, sobre todo porque es el primo de Memo. El primo Memo es un bacán con todo el mundo: les presta fierros y surte gratis de munición a más de uno, y sus escoltas son de esos tipos que por ratos trabajan para los paras.

-Eso a la final es como una empresa, dice Raúl. He visto manes que en las referencias laborales ponen haber trabajado para las Autodefensas... Donde vivo, la cucha dueña del rancho es viuda; al marido se lo pegaron en un enfrentamiento y está esperando indemnización. Los Paras dicen que le van a dar veinticinco palos de los grandes.

Y, así y todo, cuenta Raúl que él quería camellar con ellos, con la certeza de que si se aburre, puede salirse sin tropel alguno, que ellos no son como en la guerrilla, donde si alguien quiere salirse... ¡Mejor lo pegan! Memo entonces es un personaje en el pueblo, y el tío Jesús, el hermano de mi abuela... ni qué decir. Cuentan en Apartadó que don Chucho fue de los primeros comerciantes en decirles a las FARC: “... señores, iyo a ustedes no les doy un peso más!”.

Entonces, como lo conocen por esa familia, al Raúl los Paras le dijeron que no fuera a rumbiar más por allá por el Ortiz, dizque hay unos infiltrados que hay que 
cazar; pero, según parece, se tienen que llevar por lo menos a unos doscientos pa' que la cosa quede bien y se pueda volver a respirar... Debe ser por eso que últimamente han masacrado a tantos parroquianos en ese pueblo.

-Esos manes son la autoridad, y no dejan ni siquiera quemar bareta. Mariguanero mal parqueado, de una lo pegan.

Yo, la verdad, a pesar de que en el fondo lo que me llena es eso que llamaríamos profesión: sensibilidad social y política, me quedo pensando más que en los paras y su empresita de guerra, pienso en aquello de las caricias sin promesas de amor... El tío Raúl no llama a los pelados; pero espera que vengan a saludarlo... Creo que quiere tener razones para copiar algo bonito de sus hijos, como que aún lo recuerdan; pero hace mal el tío en no contribuir a un posible encuentro con sus pintas, sobre todo con el Santiago. Él es el mismo Raúl en pasta. Lo digo yo que siempre me parecí a él cuando era un niño, bueno eso es lo que dice mamita Gélica, y las tías... Pero es que Santiago se ríe como el tío, camina como el tío, corre como el tío... Es hasta barrigón como siempre lo ha sido su padre, salvo en aquella mala época en que se dejó con Patricia y se regresó a vivir con los abuelos. Es que los sentimientos y el amor, sobre todo el amor, también desgastan y acaban: desgastan los afectos y la disposición y acaban con uno... Por eso Raúl mejor se fue a ver otras tierras, a descansar de esta vereda que se lo quiere tragar a uno a las malas. Medellín es una vereda que quiere tragarnos con esas miradas escapadas que cabalgan en medio de amarguras, miradas de putas que te miran por pura necesidad... Y mi tío va de acera en acera esperando encontrar una dama que no le cobre más que la tarifa.

¿Quiere caricias que no aspiren a un futuro!

Raúl me cuenta estos deseos mientras nos tomamos unas cervezas, y después de contarme sus cosas, empieza a preguntarme...

— ¿Camellando o estudiando? ¿Qué va a hacer después? ¿Que vas a escribir un libro? Eso, siga haciendo cosas sanas. Y déjese de mariguanadas... Vea que por acá, ya están llegando también los Paras.

$\infty \infty \infty$

Para cuestionar la presencia o ausencia de los padres, se requiere avanzar más sobre tres hipótesis que se han venido planteando estudiosos de la familia en Colombia y que el profesor Hernán Henao resumía así:

La cultura antioqueña, que dejó al varón sin instrumentos para enfrentar la pérdida de su prestigio en la función del proveedor económico, que ya no está en 
capacidad de soportar sobre sus hombros. Hablamos del pasivo psicológico, social y cultural del padre.

La revolución de género, agenciada por la mujer en la lucha por su identidad como la otra, que trasciende el sexo pero lo reivindica para sí a plenitud, que le disminuye intensidad a la maternidad y en línea directa desborda el ámbito doméstico en su accionar cotidiano.

La culpabilidad de doble naturaleza, que en la crisis social se les imputa a los padres. Al varón, por su débil figura para asumir el sexo y la intensidad que requiere una cultura que se construye. $\mathrm{Y}$ a la mujer, por su reiteración del discurso apologético o mítico, en lo relacionado con la presencia del nombre del padre de la familia y la cultura.

A partir de estas tres formas de análisis me propuse dar paso a las voces de los protagonistas de esas crisis; por eso este experimento etnográfico se constituye en una plataforma polifónica, una heterogloxia que evitará que el dialogismo de Bajtin degenere en una visión trivial de múltiples voces. Por ejemplo, podemos ver la función del parcero, quien asume la tarea socializadora que descuida el padre, los saberes, los afectos, las enseñanzas acumuladas, algo extraño que si no da paso a la reflexión, porque a veces creemos que de nada sirve, deja ver la dimensión social de la familia extensa que vincula otras circunstancias. 